\title{
Flying the nest: a challenge for young adults with cystic fibrosis and their parents
}

\author{
This article was published in the following Dove Press journal: \\ Patient Preference and Adherence \\ 13 February 2017 \\ Number of times this article has been viewed
}

\author{
Vibeke Bregnballe' \\ Kirsten A Boisen ${ }^{2}$ \\ Peter Oluf Schiøtz ${ }^{3}$ \\ Tacjana Pressler ${ }^{4}$ \\ Kirsten Lomborg',5 \\ 'Department of Clinical Medicine, \\ Aarhus University, Aarhus, ${ }^{2}$ Center of \\ Adolescent Medicine, Department of \\ Pediatric and Adolescent Medicine, \\ Rigshospitalet, University Hospital \\ of Copenhagen, Copenhagen, \\ ${ }^{3}$ Department of Pediatrics, Aarhus \\ University Hospital, Aarhus, ${ }^{4}$ Cystic \\ Fibrosis Centre, Rigshospitalet, \\ University Hospital of Copenhagen, \\ Copenhagen, ${ }^{5}$ Department of Public \\ Health, Aarhus University, Aarhus, \\ Denmark
}

Objectives: As young patients with cystic fibrosis (CF) grow up, they are expected to take increasing responsibility for the treatment and care of their disease. The aim of this study was to explore the disease-related challenges faced by young adults with $\mathrm{CF}$ and their parents, when they leave home.

Materials and methods: A questionnaire survey of Danish patients with CF aged 18-25 years and their parents was conducted. The questionnaires were based on focus-group interviews with young adults with $\mathrm{CF}$ and their parents, and addressed challenges faced in the transition phase between childhood and adulthood, including different areas of disease management in everyday life.

Results: Among all of the patients invited, $62 \%(n=58 / 94)$ of young adults and $53 \%(n=99 / 188)$ of their parents participated in the study. In total, $40 \%$ of the 18 - to 25 -year-olds were living with their parents, and the parents continued to play an active role in the daily care of their offspring's disease. Among the young adults who had left home, both the patients and their parents reported many difficulties regarding disease management; the young adults reported difficulties in contacting social services and in affording and preparing sufficient CF-focused meals, and their parents reported difficulties in answering questions concerning social rights and $\mathrm{CF}$ in general, and in knowing how to give their offspring the best help, how much to interfere, and how to relinquish control of managing their offspring's disease.

Conclusion: Young adults with CF who have left home have difficulties in handling the disease and their parents have difficulties in knowing how to give them the best help. There is an urgent need for holistic CF transitional care, including ensuring that young adults master the essential skills for self-management as they leave their parents.

Keywords: chronic disease, self-management, parental support, transition

\section{Introduction}

Cystic fibrosis (CF) is a genetic, life-threatening disease that affects several major organ systems, including the respiratory, digestive, and reproductive systems. When the disease was first described, in 1938, most infants with CF died during the first year of their life. Later, life expectancy improved steadily, due to earlier diagnoses, specialized CF center care, improved medical therapy, and patient education regarding $\mathrm{CF}{ }^{1}$ Nowadays, the median age of survival of patients with CF in Denmark is 41 years. $^{2}$

$\mathrm{CF}$ requires lifelong, complex medical management. The core treatment regimen includes maintaining lung function as near to normal as possible, by controlling respiratory infections and clearing airways of mucus; administering nutritional therapy (eg, enzyme supplements, multivitamins, and mineral supplements) to maintain adequate growth; and managing complications. The treatment regimen becomes increasingly intensive over the years, as the disease progresses. Previously, patients were often hospitalized when they required treatments such as intravenous (IV) antibiotics.
Correspondence: Vibeke Bregnballe Department of Clinical Medicine, Aarhus University, Nørrebrogade 44, I2A, 8000 Aarhus C, Denmark

Tel +456169900I

Email vibebreg@rm.dk 
Currently, most treatments are administered at home to reduce hospital admissions and increase patient comfort. These treatments are administered by the parents, and as children grow up, young patients learn self-administration.

An important task in adolescence is to become independent. Although CF treatment is a heavy burden, ${ }^{3,4}$ young patients are expected and want to take responsibility for their own treatment and care. ${ }^{5}$

Much attention has been focused on transitioning of young patients from pediatric to adult health care, ${ }^{4}$ but the transition from their parents' home to their own home has received little attention. Of the few studies that have been carried out, Lowton explored experiences of lay caregiving among parents and partners of adults (18-40 years) with CF ${ }^{6}$ In Lowton's study, 31 caregivers were interviewed, and of these, 11 were parents; the author found that all the parents continued to perform some level of care for their child throughout their adult life. The parents fetched prescriptions, prepared and cleaned nebulizers, performed physiotherapy, and prepared and administered IV antibiotics. In another study, McGuffie et al found that young adults with CF continued to rely on parents for many aspects of routine care, and the dependence on parents persisted, even after they got married and they no longer lived with their parents. ${ }^{7}$

The aim of the present study was to explore the diseaserelated challenges faced by young adults and their parents, when the young adults have moved out of their parents' home. Furthermore, how much and what kind of diseaserelated support young patients with $\mathrm{CF}$ received from their parents after they had moved, was investigated.

As the present study was conducted in Denmark, a few facts about the Danish health care system should be noted. All treatment expenses of patients with CF are covered by the public sector, until the child turns 18 years old. After the age of 18 , the patient must pay the first $\approx 500 €$ per year, and the public sector will cover the remaining treatment expenses. Young patients with CF who are studying are allowed to receive a so-called "disability supplement", if the public sector cannot keep a student in job due to illness. Furthermore, they can receive food supplements, because they require more calories than their healthy peers.

\section{Materials and methods}

\section{Participants}

All of the patients aged $18-25$ years $(n=94)$ and their parents $(n=188)$ were identified via the Danish Cystic Fibrosis Registry. They were all invited by letter to participate in the study.

\section{Procedures}

Data were collected from February 2010 to June 2010 through online questionnaires. This investigation was part of a larger study designed to explore what the CF center could do to support adolescents and young adults with CF in making a successful transition to adult life.

In this study, the results for 18- to 25-year-olds were reported. The difficulties faced by the young patients in managing the disease after leaving home, the distribution of tasks associated with the disease, and adherence to treatment were investigated. Furthermore, the difficulties faced by both the young patients and their parents were also investigated.

\section{Questionnaires}

The questionnaires were based on separate focus-group interviews with young adults with $\mathrm{CF}$ and their parents, where they were asked about the challenges faced in the transition phase between childhood and adulthood. The questionnaires addressed different areas of disease management in everyday life. A multidisciplinary staff of specialists and relevant literature were consulted to evaluate the relevance of the questions. The questionnaires were pilottested in two Danish CF centers (adolescents, $n=9$; parents, $n=6)$ to evaluate whether the questions were intelligible and relevant.

The questionnaire that explored the difficulties faced by the young adults contained nine questions (Table 1). The questionnaire that explored the difficulties faced by the parents contained seven questions (Table 2). Responses were selected from a 4-point Likert scale with options from "quite right" to "quite wrong" or "do not know".

The "adherence" questionnaires contained seven questions regarding adherence to recommended daily and intermittent medical treatments; the young adults and parents responded to the same questions. Validations of the questionnaires showed Cronbach's $\alpha$ coefficients of 0.73 for the young patients' questionnaire and 0.91 for the parents' questionnaire. The test-retest reliabilities of the questionnaires were 0.86 and 0.95 , respectively, and a paired $t$-test showed no significant difference between the scores of the test and the retest. The questionnaires have been described in detail elsewhere. ${ }^{8}$ Three levels of adherence were defined: high adherence (missed the treatment no more than once during the past month), medium adherence (missed the treatment no more than once per week), and low adherence (missed the treatment more than once per week).

The questionnaire about the distribution of tasks contained the same nine questions for both the young adults and 
Table I Frequency data of young adults' reports on difficulties in managing the disease $(n=35)$

\begin{tabular}{|c|c|c|c|}
\hline Questionnaire item & $\begin{array}{l}\text { Quite or mostly } \\
\text { right, \% ( } n)\end{array}$ & $\begin{array}{l}\text { Quite or mostly } \\
\text { wrong, \% (n) }\end{array}$ & $\begin{array}{l}\text { Do not } \\
\text { know, \% (n) }\end{array}$ \\
\hline It is difficult for me to cope with everything concerning my CF treatment & $23(8)$ & $71(25)$ & $6(2)$ \\
\hline It is difficult for me to find time to take my CF treatment & $20(7)$ & $77(27)$ & $3(1)$ \\
\hline It is difficult for me to remember to take my CF treatment & $3 I(I I)$ & $69(24)$ & $0(0)$ \\
\hline It is difficult for me to afford the medicine & $23(8)$ & $74(26)$ & $3(1)$ \\
\hline It is difficult for me to afford good CF-focused meals & $40(14)$ & $54(19)$ & $6(2)$ \\
\hline It is difficult for me to get around to cooking good CF-focused meals & $43(15)$ & $46(16)$ & II (4) \\
\hline It is difficult for me to get around to getting the medicine from the pharmacy & $31(11)$ & $69(24)$ & $0(0)$ \\
\hline I do not know my rights in receiving financial support from the public sector & $46(16)$ & $48(17)$ & $6(2)$ \\
\hline $\begin{array}{l}\text { I have difficulty in contacting social services (eg, finding time to phone them } \\
\text { or understanding what they say) }\end{array}$ & $37(13)$ & $31.5(\mathrm{II})$ & $3 \mathrm{I} .5(\mathrm{II})$ \\
\hline
\end{tabular}

Abbreviation: $\mathrm{CF}$, cystic fibrosis.

their parents (Table 3). The response categories were "the young adult does it", "the parents do it", or "not relevant".

All the questionnaires were based on self-report. The online questionnaires were anonymized, but as the questionnaires were linked to data from the Danish Cystic Fibrosis Registry, it was possible for the first author, and only the first author, to recognize the individuals. The participants were informed about that.

\section{Other measures}

Two measures of health status were included: lung function, measured as the forced expiratory volume (FEV) in $1 \mathrm{~s}$, as a percentage of the predicted FEV ( $\mathrm{FEV}_{1} \%$ ); and the body mass index (BMI). Data on both the participants and nonparticipants were extracted from the National Cystic Fibrosis Registry, and all of the measures recorded in 2009 were averaged.

\section{Statistics}

Descriptive statistics were performed to describe participants' demographics, the types of difficulties, the adherence subgroups, and the degree of task-sharing. $\chi^{2}$ tests and MannWhitney $U$-tests were used to determine whether differences between participants and nonparticipants were statistically significant. Data management and analyses were performed by using Statistical Package for the Social Sciences (SPSS) Statistics Version 21. A $P$-value $<0.05$ was considered statistically significant.

\section{Ethical considerations}

The study was registered with the Danish Data Agency Board. According to Danish law, no particular permission concerning study ethics is required to conduct a study that does not include biomedical aspects; moreover, written consent from the study participants is not required for web-based questionnaire studies. Psychologists, doctors, and nurses at the CF centers were available for psychological support and treatment for patients, if needed. However, this type of support was not required during this study.

\section{Results \\ Participants}

The questionnaires were completed by $62 \%(n=58 / 94)$ of the young adults and $53 \%(n=99 / 188)$ of the parents invited to participate in this study. Table 4 lists the participant characteristics.

Of the 58 young adult participants, $55 \%(\mathrm{n}=32)$ were studying, $35 \%(\mathrm{n}=20)$ were working, $3 \%(\mathrm{n}=2)$ were on sick leave, and $7 \%(n=4)$ were on pension.

Table 2 Frequency data of parental reports on difficulties regarding their child's disease management $(n=6 \mathrm{I})$

\begin{tabular}{llll}
\hline Questionnaire item & $\begin{array}{l}\text { Quite or mostly } \\
\text { right, \% (n) }\end{array}$ & $\begin{array}{l}\text { Quite or mostly } \\
\text { wrong, \% (n) }\end{array}$ & $\begin{array}{l}\text { Do not know, } \\
\%(\mathbf{n})\end{array}$ \\
\hline It is difficult for me to know how to best assist my child & $5 I(3 I)$ & $44(27)$ & $5(3)$ \\
It is difficult for me to answer his/her questions concerning CF & $48(29)$ & $4 I(25)$ & II (7) \\
It is difficult for me to answer his/her questions concerning social rights & $67(4 I)$ & $26(16)$ & $7(4)$ \\
It is difficult for me to stand by when he/she does not adhere to treatment & $74(45)$ & $2 I(13)$ & $5(3)$ \\
It is difficult for me to know how much to interfere in my child's CF management & $54(33)$ & $43(26)$ & $3(2)$ \\
It is difficult for me to relinquish control of my child and his/her CF management & $53(32)$ & $44(27)$ & $3(2)$ \\
It is difficult for me to ask my child's permission to help him/her & $38(23)$ & $56(34)$ & $7(4)$ \\
\hline
\end{tabular}

Abbreviation: $\mathrm{CF}$, cystic fibrosis. 
Table 3 Frequency data of young adult and parental reports on degree of task-sharing in managing CF

\begin{tabular}{|c|c|c|c|c|c|c|c|}
\hline \multirow{2}{*}{$\begin{array}{l}\text { Tasks associated } \\
\text { with CF }\end{array}$} & \multirow[t]{2}{*}{ Housing status } & \multicolumn{2}{|c|}{ Adolescent does it } & \multicolumn{2}{|l|}{ Parents do it } & \multicolumn{2}{|l|}{ Not relevant } \\
\hline & & $\begin{array}{l}\text { Young } \\
\text { adults, \% (n) }\end{array}$ & $\begin{array}{l}\text { Parents, } \\
\%(n)\end{array}$ & $\begin{array}{l}\text { Young } \\
\text { adults, \% (n) }\end{array}$ & $\begin{array}{l}\text { Parents, } \\
\%(n)\end{array}$ & $\begin{array}{l}\text { Young } \\
\text { adults, \% (n) }\end{array}$ & $\begin{array}{l}\text { Parents, } \\
\% \text { (n) } \\
\end{array}$ \\
\hline Order medicine at the & Living at home & $35(8)$ & $37(14)$ & $65(15)$ & $55(21)$ & $0(0)$ & $8(3)$ \\
\hline pharmacy & Moved out of home & $87(31)$ & $82(50)$ & $9(3)$ & $13(8)$ & $3(1)$ & $5(3)$ \\
\hline Collect medicine at the & Living at home & $39(9)$ & $29(11)$ & $61(14)$ & $61(23)$ & $0(0)$ & $10(4)$ \\
\hline pharmacy & Moved out of home & $77(27)$ & $69(42)$ & $20(7)$ & $26(16)$ & $3(1)$ & $5(3)$ \\
\hline \multirow[t]{2}{*}{ Prepare for inhalation } & Living at home & $83(19)$ & $74(28)$ & $8(2)$ & $13(5)$ & $9(2)$ & $13(5)$ \\
\hline & Moved out of home & $87(3 I)$ & $79(48)$ & $0(0)$ & $3(2)$ & II (4) & $18(I I)$ \\
\hline \multirow[t]{2}{*}{ Clean up after inhalation } & Living at home & $65(15)$ & $50(19)$ & $26(6)$ & $37(14)$ & $9(2)$ & $13(5)$ \\
\hline & Moved out of home & $89(31)$ & $74(45)$ & $0(0)$ & $5(3)$ & II (4) & $21(13)$ \\
\hline Collect the PEP mask when & Living at home & $87(20)$ & $28(26)$ & $0(0)$ & $3(1)$ & $13(3)$ & $29(\mathrm{II})$ \\
\hline time for pepping & Moved out of home & $87(3 \mathrm{I})$ & $70(43)$ & $0(0)$ & $2(1)$ & II (4) & $28(17)$ \\
\hline \multirow[t]{2}{*}{ Cleaning the PEP mask } & Living at home & $48(11)$ & $26(10)$ & $30(7)$ & $42(16)$ & $22(5)$ & $32(12)$ \\
\hline & Moved out of home & $86(30)$ & $64(39)$ & $3(I)$ & $5(3)$ & II (4) & $31(19)$ \\
\hline Prepare IV antibiotic & Living at home & $30(7)$ & $13(5)$ & $17(4)$ & $42(16)$ & $53(12)$ & $45(17)$ \\
\hline treatment & Moved out of home & $63(22)$ & $57(35)$ & $14(5)$ & $18(11)$ & $23(8)$ & $25(15)$ \\
\hline \multirow[t]{2}{*}{ Clean up after IV treatment } & Living at home & $26(6)$ & $16(6)$ & $22(5)$ & $37(14)$ & $52(12)$ & $47(18)$ \\
\hline & Moved out of home & $66(23)$ & $56(34)$ & II (4) & $20(12)$ & $23(8)$ & $24(15)$ \\
\hline Notice when medicine is & Living at home & $57(13)$ & $47(18)$ & $44(10)$ & $45(17)$ & $0(0)$ & $8(3)$ \\
\hline running out & Moved out of home & $91(32)$ & $80(49)$ & $9(3)$ & $12(7)$ & $0(0)$ & $8(5)$ \\
\hline
\end{tabular}

Abbreviations: CF, cystic fibrosis; IV, intravenous; PEP, positive expiratory pressure.

\section{Difficulties faced by young adults and parents}

Of the participating 18 - to 25 -year-olds, $60 \%(n=35 / 58)$ had moved out of their parents' home. These young adults were asked about difficulties after leaving home, and they reported many difficulties related to managing the disease (Table 1). Nearly half of these participants reported that they did not know their rights concerning financial support from the public sector, $\sim 40 \%$ of the participants reported difficulties in contacting social services (eg, either difficulty in finding time to phone them or difficulty in understanding what they said), and $\sim 40 \%$ reported difficulty affording and preparing nutritious CF-focused meals. No significant difference in BMI was found between patients who did and those who did not report difficulties.
A majority of parents reported difficulties regarding their child's disease (Table 2); 62\% ( $\mathrm{n}=61 / 99)$ of the parents had 18- to 25 -year-olds who had moved out of the house. These parents were asked about difficulties regarding the disease; $64 \%$ of these parents reported difficulties answering questions about social rights. About half of the parents reported difficulties, for example, in answering questions about $\mathrm{CF}$, in knowing how to best assist their child, how much to interfere, and in relinquishing control of their child's disease management.

\section{Adherence}

The young adults who had moved out of their home reported lower adherence than those living at home (Table 5), but the difference was not statistically significant $(P=0.064)$.

Table 4 Characteristics of participants, nonparticipants, and retested participants

\begin{tabular}{|c|c|c|c|}
\hline Characteristics & Participants & Nonparticipants & Significance (two-tailed) \\
\hline Young adults (n) & 58 & 36 & \\
\hline Male/female (\%) ${ }^{\mathrm{a}}$ & $38 / 62$ & $61 / 39$ & 0.048 \\
\hline Living at home/moved out of home (\%) & $40 / 60$ & $59 / 41$ & 0.118 \\
\hline Age $(\text { years, mean } \pm S D)^{b}$ & $21.2 \pm 1.9$ & $20.9 \pm 2.6$ & 0.358 \\
\hline Age $(\text { years, mean } \pm S D)^{b}$ of the young & $20.1 \pm 1.4 / 22.0 \pm 1.8$ & & \\
\hline \multicolumn{4}{|l|}{ adults living at home/moved out of home } \\
\hline $\mathrm{FEV}_{1} \%(\text { mean } \pm \mathrm{SD})^{\mathrm{b}}$ & $83.5 \pm 23.5$ & $72.7 \pm 26.0$ & 0.054 \\
\hline BMI $\left(\mathrm{kg} / \mathrm{m}^{2}, \text { mean } \pm \mathrm{SD}\right)^{\mathrm{b}}$ & $21.5 \pm 3.6$ & $20.1 \pm 2.8$ & 0.082 \\
\hline Parents $(n)$ & 99 & 89 & \\
\hline Male/female (\%) ${ }^{\mathrm{a}}$ & $45 / 55$ & $55 / 45$ & 0.243 \\
\hline Child's FEV $\%$ (mean \pm SD) ${ }^{\mathrm{b}}$ & $82.2 \pm 25.1$ & $76.3 \pm 24.4$ & 0.078 \\
\hline
\end{tabular}

Notes: aPearson $\chi^{2}$; bindependent-samples Mann-Whitney U-test.

Abbreviations: BMI, body mass index; FEV \%, forced expiratory volume in I s as a percentage of predicted FEV; SD, standard deviation. 
Table 5 Frequency data of young adult and parental reports on adherence among young adults who live at home or out of the home

\begin{tabular}{|c|c|c|c|c|}
\hline \multirow[t]{2}{*}{ Adherence level } & \multicolumn{2}{|c|}{ Young adult perspective } & \multicolumn{2}{|l|}{ Parent perspective } \\
\hline & $\begin{array}{l}\text { Living at } \\
\text { home, \% (n) }\end{array}$ & $\begin{array}{l}\text { Moved out of } \\
\text { the home, \% (n) }\end{array}$ & $\begin{array}{l}\text { Their child lived at home, } \\
\%(n) \text { of parents }{ }^{a}\end{array}$ & $\begin{array}{l}\text { Their child had moved out of } \\
\text { the home, } \%(n) \text { of parents }\end{array}$ \\
\hline High adherence & $48(1 \mathrm{I})$ & $43(15)$ & $56(19)$ & $57(27)$ \\
\hline Medium adherence & $48(\mathrm{II})$ & $3 I(I I)$ & $35(12)$ & $30(14)$ \\
\hline Low adherence & $4(1)$ & $26(9)$ & $9(3)$ & $13(6)$ \\
\hline
\end{tabular}

Notes: aFour out of 38 parents answered "do not know"; b/4 out of 47 parents answered "do not know".

The number of young adults with high adherence was almost the same among young adults living at home compared with the young adults who had moved out, but the number of young adults with low adherence was much higher in the moved-out-of-home group than in the living-at-home group, but still not statistically significant. According to the parents' reports, adherence was not significantly different between these two groups (Table 5).

\section{Distribution of tasks associated with disease management}

Both the 18- to 25-year-olds who lived at home and those who had left home received help from their parents (Table 3). Those who lived at home received help in ordering and collecting medicine at the pharmacy, cleaning up after inhalation, cleaning the positive expiratory pressure mask, preparing and cleaning up after IV antibiotic treatments, and noticing when their medicine was running out; $\sim 20 \%$ of the young adults who had moved out of home received help in collecting medicine at the pharmacy, and $10 \%-15 \%$ received help in preparing and cleaning up after IV treatment and noticing when their medicine was running out.

The young adults and their parents roughly agreed on how the tasks associated with disease management were shared between them.

\section{Discussion}

This study showed that both young adults and their parents experienced many challenges when the young adults had left home.

Young adults living at home received help in maintaining the supply of medicine and preparing and cleaning up after treatment. These findings were consistent with the findings previously reported by Iles and Lowton, ${ }^{9}$ based on interviews with 32 young people (aged 16-24 years) with $\mathrm{CF}$, with the majority ( $\mathrm{n}=24)$ of them living with their parents. The study by Iles and Lowton documented that the majority of young people received some form of practical and emotional support from their parents in ongoing disease management.
In the present study, it was found that young adults who had moved out of their parents' home continued to receive help from their parents; $20 \%$ reported receiving help in collecting medicine at the pharmacy, and 10\%-15\% received help in preparing and cleaning up after IV treatments and noticing when their medicine was running out. These findings were consistent with the previous reports. Lowton found that all parents continued to help their offspring throughout their adult life; for example, they fetched prescriptions and prepared and administered IV antibiotics. ${ }^{6}$ McGuffie et al found that young adults with $\mathrm{CF}$ depended on their parents, even after they married and they no longer lived with their parents. ${ }^{7}$ The most common reason for administering IV antibiotic treatment is disease exacerbation; thus, the patient feels unwell and tired and lacks energy. Many CF centers routinely allow home IV treatment; thus, patients must, and often want to, manage the treatment themselves. However, IV administration can be challenging when the person is feeling unwell and tired; this situation might explain why the parents provide help, even after the young adult has moved out of the house. In addition, it is natural for most parents to help their offspring, regardless of whether they have a chronic condition.

Approximately $40 \%$ of young adults reported difficulties in cooking and affording nutritious CF-focused meals. However, this did not seem to influence the BMI of young patients; BMIs were not significantly different between patients who did and those who did not report difficulties. Nearly half of the young adults did not know their rights regarding financial support from the public sector. In addition, about half of them reported difficulties in contacting social services. Information about $\mathrm{CF}$ and how to manage it is routinely provided to parents of pediatric patients. However, this information may not always be repeated to the child when he/she grows up. Thus, the parents are responsible for passing on information about the disease and the management of the disease to their offspring. In the present study, the adolescents had received education regarding CF during childhood; however, the information was not routinely 
or regularly repeated; therefore, the young adults lacked information about the disease and self-management. ${ }^{10,11}$

Health professionals working with adolescents with a chronic disease often focus on educating the patients in topics strictly concerning the disease. This communication is crucial for the patients to learn how to control the disease. Nevertheless, often health professionals fail to train adolescents in self-management skills, for example, how to communicate with the healthcare system, understand social services, cook good CF-focused meals, and, in general, live with a chronic disease. ${ }^{12,13}$ Evidence from the previous studies were consistent with the findings from the present study, which suggested that a holistic approach is needed to help adolescents and young adults with a chronic disease in the transition into adult life. Health professionals must ensure that young patients master the knowledge and skills essential for self-management of the disease. ${ }^{10,11,14-16}$

The present study found that the parents also lacked knowledge. About half of them reported difficulties in answering their offspring's questions about $\mathrm{CF}$, and $64 \%$ reported difficulties in answering questions about social rights. As the children grow up, health professionals tend to focus on teaching the adolescent about the disease, and the parents fade into the background. This change is natural, but the parents may be caught in a situation where it might be difficult for them to update their own knowledge. This emphasizes the necessity of reeducating the parents, in addition to educating adolescents and young adults with CF. ${ }^{11}$

The parents also reported difficulties in knowing how best to help their offspring, how much to interfere, and how to relinquish control of their offspring's disease management. As the child with CF grows up, the parents' role must shift from being in charge of the treatment to being a kind of coach. This change in role is not an easy transition for the parents. ${ }^{14}$ In a previous study, it was found that parents might have difficulty in finding a balance between their need to maintain control and the adolescents' need for autonomy. ${ }^{5}$ Furthermore, parents rarely receive guidance in the art of transitioning from the role of the responsible parent to the role of a mentor or coach. ${ }^{15}$ Thus, parents need support from health professionals in learning to promote self-management for their offspring and, at the same time, in feeling confident in handing over the responsibility. ${ }^{14,16,17}$

Young adults who had moved out of home reported lower adherence than those living at home, but the difference was not statistically significant. Moreover, the self-reported adherence was higher than in other studies. A recent Danish study showed that adherence to treatment declined among young adults with
CF after leaving home. ${ }^{18}$ In that study, the participants' mean age was higher than the age of the present cohort, they were recruited from only one of two Danish CF centers, and the Morisky Medication Adherence Scale ${ }^{19}$ was used to measure adherence. These differences in the study design might explain the discrepancy in the levels of adherence between the studies. In adolescence, a decline in adherence is often observed, ${ }^{20,21}$ and several barriers to adherence have been identified. ${ }^{8,22-24}$ It may be difficult for young adults to maintain high adherence, particularly when the treatment burden is heavy and the parents are not around to help. ${ }^{3}$ Other studies have shown that premature withdrawal of parental involvement may be associated with poor outcomes and poor adherence. ${ }^{25,26}$ However, parental withdrawal after a young adult has moved out of the parents' house should not be considered premature. These findings suggested that full autonomy is a heavy burden for young adults with chronic conditions and that they may need support to deal with the burden. ${ }^{12}$ The findings also emphasize the importance of supporting the parents in balancing involvement and relinquishment at an early stage in the transition, before their offspring leave home.

\section{Limitations}

This study had some limitations. It can be argued that the sample size was small; however, the whole Danish cohort was invited to participate, and more than half of them accepted, which is acceptable. Participants differed from nonparticipants in two ways: participants had higher $\mathrm{FEV}_{1}$ values and more were female, but only the gender difference was significant. The questions concerning difficulties faced by young adults in managing the disease (Table 1) were only asked to those who had moved out of their parents' home and their parents. The young adults living at home and their parents were not asked these questions. It would have been interesting to explore whether those young adults and their parents faced the same difficulties as the young adults who had moved out and their parents, but then the age difference in the two groups should be taken into consideration. This could be the aim of a future study.

Adherence is difficult to measure, and no measure of adherence is $100 \%$ reliable. Electronic monitoring, daily phone diaries, and prescription refill history are other methods to measure adherence, but they require electronic monitoring equipment or more resources than those available in this study. However, using several methods could have provided a more exact measure of the young adults' adherence.

It can also be claimed that using validated questionnaires would have been a better choice, but no questionnaires that fit with the present research question were found. 
In this study, young adults with $\mathrm{CF}$ and the challenges they face when they leave their parents' home were focused. It should be mentioned that CF not necessarily is the one and only reason for all the challenges the young adults face. This could be addressed in a future study.

\section{Conclusion}

This questionnaire survey investigated the difficulties facing young adults with $\mathrm{CF}$ and their parents when the young adults moved out of home. Both young adults and their parents reported challenges during this phase of life. Parents continued to play an important role in supporting the young adults in managing the disease in everyday life. For example, parents often administered the home IV antibiotic treatment. Young adults lacked knowledge and skills needed for full self-management, and the parents were not confident that they knew the best way to support their offspring. These results suggested that health professionals need to inform adolescents and young adults and their parents repeatedly about the disease and train them in self-management. Furthermore, a mechanism to support parents in finding the difficult balance between controlling and letting go of their child's CF management is needed.

\section{Acknowledgments}

This study was supported by three grants: one from The Danish CF Association, one from the Novo Nordisk Foundation, and one from The Danish Nurses' Organization Foundation. The authors are grateful to the patients and families who participated in this research.

\section{Disclosure}

The authors report no conflicts of interest in this work.

\section{References}

1. Orenstein DM, Winnie GB, Altman H. Cystic fibrosis: a 2002 update. $J$ Pediatr. 2002;140(2):156-164.

2. Ravilly S, Olesen HV, Quinton HB, et al. Study on cystic fibrosis mortality in 5 countries. J Cyst Fibros. 2005;4 (Suppl 1):S119-S125.

3. Sawicki GS, Sellers DE, Robinson WM. High treatment burden in adults with cystic fibrosis: challenges to disease self-management. J Cyst Fibros. 2009;8(2):91-96.

4. Badlan K. Young people living with cystic fibrosis: an insight into their subjective experience. Health Soc Care Community. 2006;14(3): 264-270.

5. Bregnballe V, Schiøtz PO, Lomborg K. Parenting adolescents with cystic fibrosis: the adolescents' and young adults' perspectives. Patient Prefer Adherence. 2011;5:563-570.

6. Lowton K. Parents and partners: lay carers' perceptions of their role in the treatment and care of adults with cystic fibrosis. J Adv Nurs. 2002;39(2): 174-181.

7. McGuffie K, Sellers DE, Sawicki GS, Robinson WM. Self-reported involvement of family members in the care of adults with CF. J Cyst Fibros. 2008;7(2):95-101.
8. Bregnballe V, Schiøtz PO, Boisen KA, Pressler T, Thastum M. Barriers to adherence in adolescents and young adults with cystic fibrosis: a questionnaire study in young patients and their parents. Patient Prefer Adherence. 2011;5:507-515.

9. Iles $\mathrm{N}$, Lowton $\mathrm{K}$. What is the perceived nature of parental care and support for young people with cystic fibrosis as they enter adult health services? Health Soc Care Community. 2010;18(1):21-29.

10. Sawicki GS, Sellers DE, McGuffie K, Robinson W. Adults with cystic fibrosis report important and unmet needs for disease information. J Cyst Fibros. 2007;6(6):411-416.

11. Dashiff C, Suzuki-Crumly J, Kracke B, Britton L, Moreland E. Cystic fibrosis-related diabetes in older adolescents: parental support and self-management. J Spec Pediatr Nurs. 2013;18(1):42-53.

12. Sattoe JNT, Hilberink SR, van Staa A, Bal R. Lagging behind or not? Four distinctive social participation patterns among young adults with chronic conditions. J Adolesc Health. 2014;54(4):397-403.

13. Sattoe JNT, Bal MI, Roelofs PDDM, Bal R, Miedema HS, van Staa A. Self-management interventions for young people with chronic conditions: a systematic overview. Patient Educ Couns. 2015;98(6): 704-715.

14. Williams B, Mukhopadhyay S, Dowell J, Coyle J. From child to adult: an exploration of shifting family roles and responsibilities in managing physiotherapy for cystic fibrosis. Soc Sci Med. 2007;65(10): 2135-2146.

15. Steinberg L. We know some things: parent-adolescent relationships in retrospect and prospect. J Res Adolesc. 2001;11(1):1-19.

16. Sawyer SM. Self-management in adolescents with chronic illness. What does it mean and how can it be achieved? Med J Aust. 2005; 183(8):405-409.

17. Hafetz J, Miller VA. Child and parent perceptions of monitoring in chronic illness management: a qualitative study. Child Care Health Dev. 2010;36(5):655-662.

18. Knudsen KB, Pressler T, Mortensen LH, et al. Associations between adherence, depressive symptoms and health-related quality of life in young adults with cystic fibrosis. Springerplus. 2016;5(1):1216.

19. Morisky DE, Ang A, Krousel-Wood M, Ward HJ. Predictive validity of a medication adherence measure in an outpatient setting. $J$ Clin Hypertens (Greenwich). 2008;10(5):348-354.

20. Zindani GN, Streetman DD, Streetman DS, Nasr SZ. Adherence to treatment in children and adolescent patients with cystic fibrosis. $J$ Adolesc Health. 2006;38(1):13-17.

21. Masterson TL, Wildman BG, Newberry BH, Omlor GJ. Impact of age and gender on adherence to infection control guidelines and medical regimens in cystic fibrosis. Pediatr Pulmonol. 2011;46(3):295-301.

22. Dziuban EJ, Saab-Abazeed L, Chaudhry SR, Streetman DS, Nasr SZ. Identifying barriers to treatment adherence and related attitudinal patterns in adolescents with cystic fibrosis. Pediatr Pulmonol. 2010; 45(5):450-458.

23. George M, Rand-Giovannetti D, Eakin MN, Borrelli B, Zettler M, Riekert KA. Perceptions of barriers and facilitators: self-management decisions by older adolescents and adults with CF. J Cyst Fibros. 2010; $9(6): 425-432$.

24. Hanghøj S, Boisen KA. Self-reported barriers to medication adherence among chronically ill adolescents: a systematic review. J Adolesc Health. 2014;54(2):121-138.

25. Modi AC, Marciel KK, Slater SK, Drotar D, Quittner AL. The influence of parental supervision on medical adherence in adolescents with cystic fibrosis: developmental shifts from pre to late adolescence. Child Health Care. 2008;37(1):78-92.

26. Wysocki T, Greco P. Social support and diabetes management in childhood and adolescence: influence of parents and friends. Curr Diab Rep. 2006;6(2):117-122. 
Patient Preference and Adherence

Dovepress

\section{Publish your work in this journal}

Patient Preference and Adherence is an international, peer-reviewed, open access journal that focuses on the growing importance of patient preference and adherence throughout the therapeutic continuum. Patient satisfaction, acceptability, quality of life, compliance, persistence and their role in developing new therapeutic modalities and compounds to optimize

clinical outcomes for existing disease states are major areas of interest for the journal. This journal has been accepted for indexing on PubMed Central. The manuscript management system is completely online and includes a very quick and fair peer-review system, which is all easy to use. Visit http://www. dovepress.com/testimonials.php to read real quotes from published authors.

Submit your manuscript here: http://www.dovepress.com/patient-preference-and-adherence-journal 